\title{
State-of-the-art surgery for sigmoid diverticulitis
}

\author{
Roberto Cirocchi ${ }^{1}$ (1) Paolo Sapienza ${ }^{2}$. Gabriele Anania ${ }^{3} \cdot$ Gian Andrea Binda $^{4,1}$ - Stefano Avenia ${ }^{1}$. \\ Salomone di Saverio ${ }^{5} \cdot$ Giovanni Domenico Tebala $^{6} \cdot$ Mauro Zago $^{7} \cdot$ Annibale Donini $^{1} \cdot$ Andrea Mingoli $^{2}$. \\ Riccardo Nascimbeni ${ }^{8}$
}

Received: 27 June 2021 / Accepted: 27 July 2021 / Published online: 23 September 2021

(c) The Author(s) 2021

\begin{abstract}
Summary
Background In the last two decades, there has been a Copernican revolution in the decision-making for the treatment of Diverticular Disease.

Purpose This article provides a report on the state-of-the-art of surgery for sigmoid diverticulitis.

Conclusion Acute diverticulitis is the most common reason for colonic resection after cancer; in the last decade, the indication for surgical resection has become more and more infrequent also in emergency. Currently, emergency surgery is seldom indicated, mostly for severe abdominal infective complications. Nowadays, uncomplicated diverticulitis is the most frequent presentation of diverticular disease and it is usually approached with a conservative medical treatment. Non-Operative Management may be considered also for complicated diverticulitis with abdominal abscess. At present, there is consensus among experts that the hemodynamic response to the initial fluid resuscitation should guide the emergency surgical approach to patients with severe sepsis or septic shock. In hemodynamically stable patients, a laparoscopic approach is the first choice, and surgeons with advanced laparoscopic skills report advantages in terms of lower postoperative complication rates. At the moment, the so-called Hartmann's procedure is only indicated in severe generalized peritonitis with metabolic derangement or in severely ill patients. Some authors suggested laparoscopic peritoneal lavage as a bridge to surgery or also as a definitive treatment without colonic resection in selected patients. In case of hemodynamic instability not responding to fluid resuscitation, an initial damage control surgery seems to be more attractive than a Hartmann's procedure, and it is associated with a high rate of primary anastomosis.
\end{abstract}

Keyword Diverticular disease $\cdot$ Acute diverticulitis $\cdot$ Management $\cdot$ Surgical treatment

\section{Quick reference/description}

Sigmoid and left colonic diverticula are "pockets" of mucosa, submucosa, and serosa herniated from the bowel wall; in the western world, they present more often in the sigmoid, due to the intraluminal high pressure and the presence of weak spots in the muscular layer [1]. Colonic diverticulosis may be symptomatic; this heterogeneous condition is called Diverticular Disease (DD) and may be due to acute diverticulitis (AD) or persistent abdominal symptoms (abdominal pain, bloating, and changes in bowel habits) in the absence of macroscopic inflammation (SUDD = symptomatic uncomplicated diverticular disease). More often,

Roberto Cirocchi

roberto.cirocchi@unipg.it

Extended author information available on the last page of the article it is an uncomplicated $\mathrm{AD}$, but in some cases, an $\mathrm{AD}$ can become complicated with abscess, peritonitis, stricture, or hemorrhage (Fig. 1).

\section{Overview}

In the Western population, DD is a quite common condition over the age of 50 (50\% of the population). The sigmoid colon is the most frequent localization $(65 \%)$, other uncommon locations being the sigmoid plus other parts of the large bowel (25\%) or the entire colon (7\%) [2]. Acute diverticulitis is the most common surgically treated disease after cancer; in the last three decades, the indications for surgical resection progressively reduced, in particular for the elective resection, and nowadays, elective surgery is considered only in the few cases with persistent symptoms and 
Fig. 1 The natural history of diverticulitis

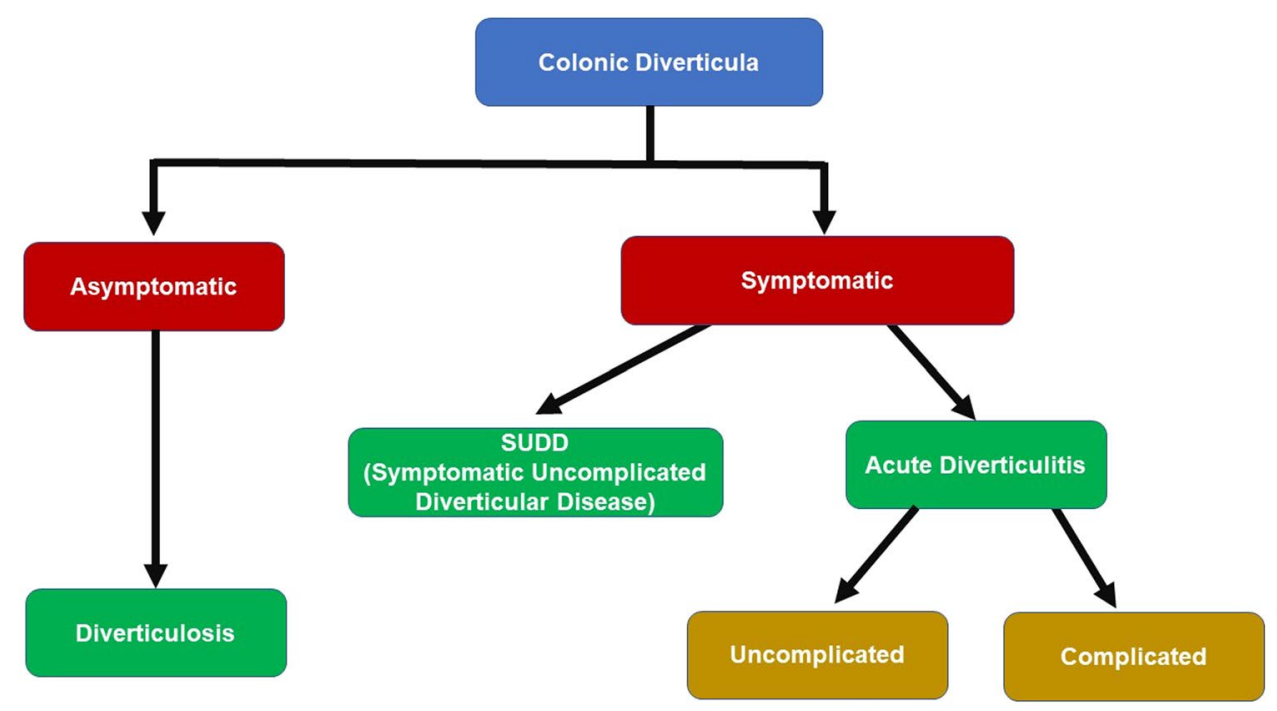

the risk of recurrent acute episodes in particular in young patients. Likewise, also, the indications for emergency surgery are quite restricted and limited to very selected cases (8.3\%) [3] mostly for severe abdominal infective complications $(41.62-79.4 \%)[4,5]$.

\section{Anatomical considerations}

The sigmoid is the last part of the colon and its morphology can be highly variable (length of S-shaped loop between 11.9 and $91.1 \mathrm{~cm}$, width of the sigmoid mesocolon between 4 and $11.5 \mathrm{~cm}$ ) [6]. In common clinical practice, these variants may explain the heterogeneous clinical picture and the sometimes atypical presentation with right lower quadrant (RLQ) pain from sigmoid diverticulitis associated with a long and redundant colon [7].

\section{Indications for non-operative treatment or surgery}

\section{Acute uncomplicated diverticulitis}

The last few decades saw a revolution in the decisionmaking process for acute uncomplicated diverticulitis [1]. In the 1990s, guidelines suggested considering an elective colonic resection at the second clinical episode of severe diverticulitis [8], based on the high recurrence rate after the first episode (13.3\%) and after the second episode (29.3\%) [9]. This recommendation was based on the paper published by Parks in the 1960s, reporting data of 455 patients who had recurrent symptoms of acute diverticulitis in 7 to $45 \%$ of cases and only $6 \%$ of them responded to medical therapy after the third episode [10].
In the 1990s, the American Society of Colon and Rectal Surgery (ASCRS) ("Thus, after two attacks of uncomplicated diverticulitis, resection is recommended. Resection is also recommended for patients with complicated diverticulitis after one attack") [11] and the European Association for Endoscopic Surgery ("Patients should be considered for elective surgery if they have had at least two attacks of symptomatic diverticular disease") [12] supported the opinion of Parks, although it was not associated with robust scientific evidence [13]. In the same period, the Society for Surgery of the Alimentary Tract [14] categorized the indications for elective sigmoid resections: two or more severe acute attacks of diverticulitis despite successful medical treatment, single attack requiring hospitalization in a patient aged less than 40 years, one attack with evidence of contained perforation, colonic obstruction, or inflammatory involvement of the urinary tract and inability to rule out a colonic carcinoma.

Subsequently, other studies prompted the ASCRS to change the old paradigm to new statement, where the surgical option was decided case-by-case [15] ("The decision to recommend elective sigmoid colectomy after recovery from uncomplicated acute diverticulitis should be individualized") [16, 17], effectively abandoning the number of attacks of colonic diverticulitis as a determinant of the surgical strategy [11]. In the ensuing years, other guidelines and statements supported this tailored approach ("Elective surgery to prevent complicated disease is not justified, irrespective of the number of previous attacks"... "The goal of elective surgery after one or more episodes of diverticulitis is to improve QoL. The indication should be individualized and based on the frequency of recurrences, duration, and severity of symptoms after the attacks and the comorbidity of the patient") [18].

Nowadays, the uncomplicated diverticulitis (modified Hinchey 0 and IA, phlegmon, SUDD) is the most frequent 
diverticular condition, and it is commonly treated with antibiotics only, although recent studies demonstrated that in selected patients, antibiotics may not be necessary [19]. Nowadays, Non-Operative Treatment (NOT) is also considered for patients with complicated diverticulitis with abscess (modified Hinchey IB and II) [20], but this strategy is associated with a risk of failure (18.6\%) [21] (Fig. 2).

ASCRS and ESCP guidelines suggest antibiotic therapy covering both Gram-negative and anaerobic bacteria [22] This can be enough for small pericolic abscesses but should be associated to percutaneous drainage for large accessible pelvic abscesses $[17,18]$. In the common clinical practice, an abscess is considered to be "large" if its diameter is more than 3-5 cm (image-guided percutaneous drainage is usually recommended for stable patients with abscesses $>3 \mathrm{~cm}$ in size) $[17,18]$ "We suggest to treat patients with large abscesses with percutaneous drainage combined with antibiotic treatment; whenever percutaneous drainage of the abscess is not feasible or not available, we suggest to initially treat patients with large abscesses with antibiotic therapy alone, clinical conditions permitting. Alternatively, operative intervention is required" [23, 24]. They are usually associated with a higher rate of recurrence [22].

During NOT, it is very important to set up a strict followup with repeated clinical evaluations, US, and laboratory analyses, to be able to spot the early signs of worsening clinical conditions, which may demonstrate the failure of the NOT. As suggested by Hanna and Kaiser, "within $72 \mathrm{~h}$ after initiation of appropriate treatment, symptoms, and objective parameters (pain, fever, leucocytosis, systemic inflammatory response syndrome (SIRS), etc.) must improve without exception or completely resolve/normalize" [25]. In the suspect of NOT failure, a prompt reply action is needed as previously reported by Hanna and Kaiser: "Repeat imaging to discern whether a drainable abscess has formed or a surgical intervention" [25].

In these patients, a surgical operation is needed only in case of "failure of percutaneous drainage and/or antibiotics, and in a critically ill or deteriorating patient" [26].

Although most of the acute diverticulitis cases $(>70 \%)$ are uncomplicated [25], the indications for elective surgical treatment in patients with acute uncomplicated diverticulitis are still object of controversy. Elective colonic resection has some advantages, including the very low risk of colonic perforation $(5.5 \%)$ [27].

The DIRECT trial [28] reported an improvement of the Quality of Life (QoL) in patients who underwent surgery, and recently, the LASER trial [29] reported better results than conservative management. However, the Achille's heel of elective surgery is represented by the risk of postoperative complications and the risk of recurrence of diverticulitis. In the DIRECT trial [28], 11\% of surgically treated

\section{Acute diverticulitis (modified Hinchey 0 and IA, phlegmon, SUDD) or Diverticular Abscess (modified Hinchey IB and II)}

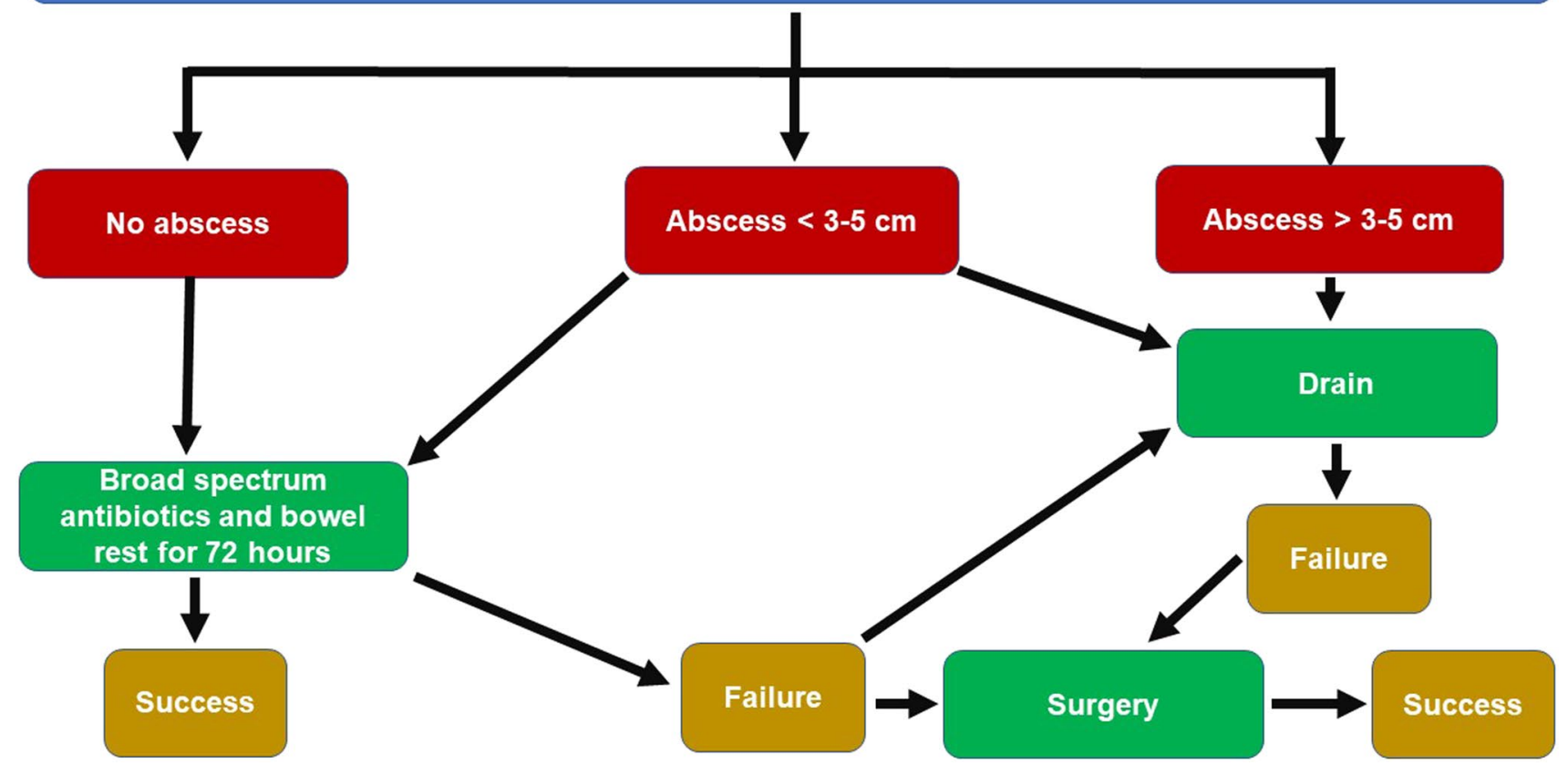

Fig. 2 Treatment algorithm for patients with acute uncomplicated diverticulitis (modified Hinchey 0 and IA, phlegmon, SUDD) or diverticular abscess (modified Hinchey IB and II) 
patients had anastomotic leak and $15 \%$ required reoperation at 5 years. The LASER trial reported lower rates of major post-operative complications (Clavien-Dindo grade III or higher in $5 \%$ of cases) and of recurrent diverticulitis within 6 months (31\%).

Nowadays, on the basis of these results, the decision to consider an elective surgical resection in patients with recurrent uncomplicated diverticulitis is to be taken on a case-bycase basis considering frequency of recurrences, duration and severity of symptoms, postoperative QoL, immunosuppression, surgical risk score, and patient values [29-31].

In uncomplicated acute diverticulitis, the key point is to identify the patients who may benefit of an elective surgical resection and those who on the contrary present a high risk of surgical morbidity and mortality. The latter should be considered for a long-term medical treatment. In any case, the therapeutic choice must arise from a frank and informed discussion with the patients [22].

\section{Acute complicated diverticulitis}

In patients with acute complicated diverticulitis, severe septic complications are the most common cause of emergency surgical treatment.

Acute generalized peritonitis (Hinchey III or IV) or abscess (Hinchey IIb) associated with sepsis are timedependent emergencies, in which a delay of the treatment is inversely related with prognosis $[33,34]$. The International Guidelines for Management of Sepsis and Septic Shock suggest, in fact, hemodynamic optimization and emergency surgical treatment as soon as possible [35]. Initial resuscitation is based on the hemodynamic response to fluid bolus [36] of $30 \mathrm{~mL} / \mathrm{kg}$ [37] while previous evidence suggested a fixed bolous of crystalloids of $500 \mathrm{~mL}$ (fluid challenge) [38]. According to the mentioned guidelines, "fluid administration beyond initial resuscitation requires careful assessment of the likelihood that the patient remains fluid responsive" [35]. The use of vasoactive agents, such as norepinephrine, is mandatory in the absence of a significant compensative response to fluid resuscitation [39].

Nowadays, there is consensus [40,41] on the fact that the emergency surgical approach to patients with sepsis and septic shock must be tailored on the basis of the hemodynamic conditions of the patient after an appropriate fluid resuscitation, as follows (Fig. 3):

\section{Hemodynamically stable}

For almost a century, the "ideal surgical treatment" for hemodynamically stable patients with acute complicated diverticulitis has been the Hartmann's procedure (HP) [42]. More recently, some observational studies supported the immediate primary resection and anastomosis (PRA). Constantinides et al. performed a systematic review and

\section{Acute generalized peritonitis (Hinchey III or IV) or abscess (Hinchey IIb) associated with sepsis}

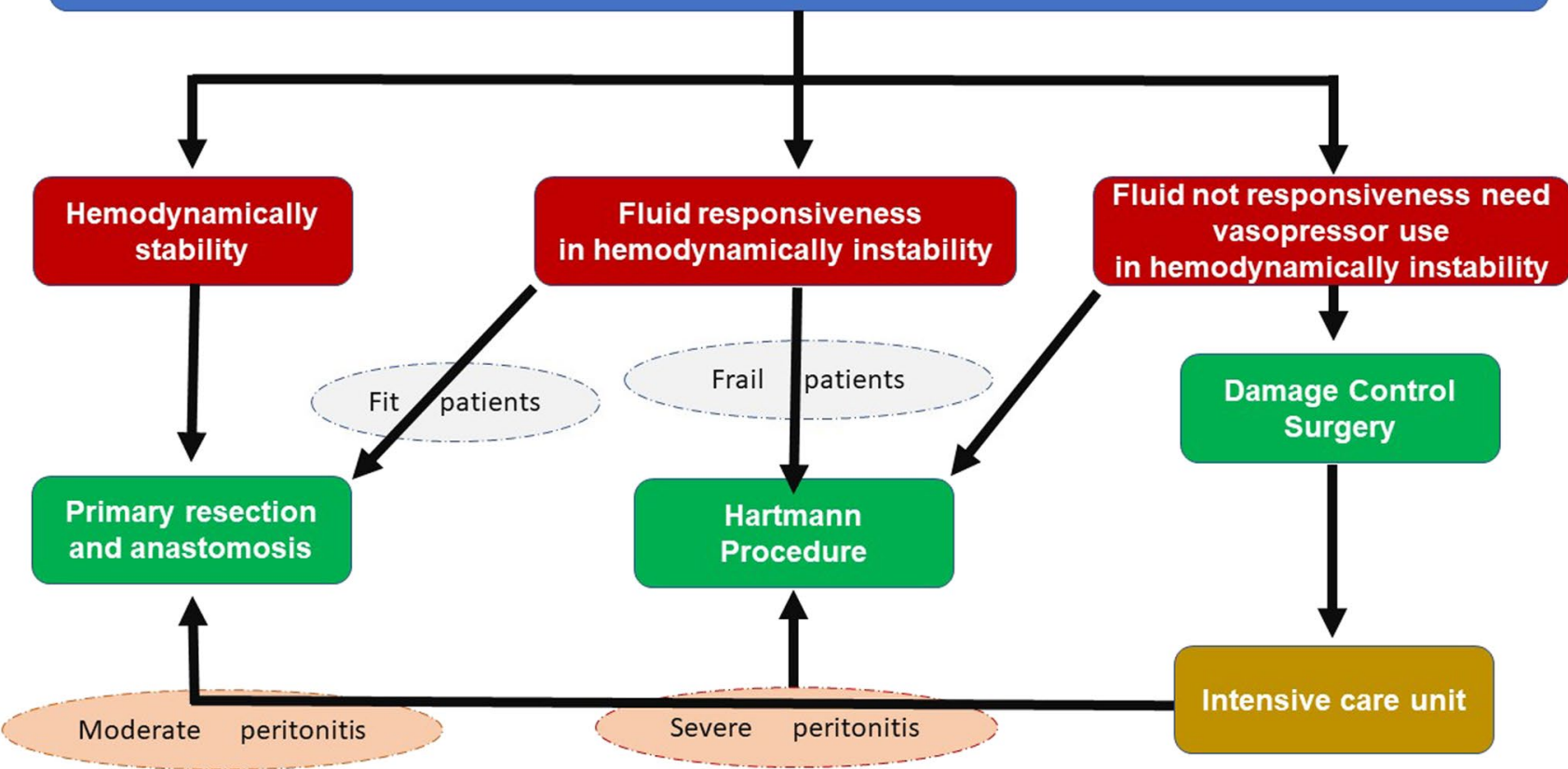

Fig. 3 Treatment algorithm for patients with diverticular perforation and diffuse peritonitis (modified from Nascimbeni et al.: Management of perforated diverticulitis with generalized peritonitis. A multidisciplinary review and position paper) [40] 
meta-analysis clearly demonstrating the advantages of PRA with respect to the HP in terms of post-operative mortality, surgical site infections, abscesses, and peritonitis [43]. The main limitation of this review was the high risk of selection bias due to the retrospective nature of the included studies [43]. In the last decade, four RCTs were performed with the aim to compare PRA vs HP [44-47]. Lambrichts et al. reported the results of a meta-analysis of these four RCTs [48], showing that PRA is superior to HP as regards to the number of stoma-free patients (OR $0.33,95 \%$ CI $0.16-0.69$ ) (Fig. 4), stoma reversal rates (OR 2.62, 95\% CI 1.29-5.31), and reversal-related morbidity (OR $0.33,95 \% \mathrm{CI} 0.16,0.69$ ), but there was no difference in short-term mortality (OR 0.83 , 95\% CI 0.32- 2.19) (Fig. 5), overall morbidity (OR 0.99, 95\% CI 0.65, 1.51) (Fig. 6), and reintervention rates after the index procedure (OR 0.90, 95\% CI 0.39-2.11).

Recent evidence suggests that the HP should only be indicated in severe generalized peritonitis or in critically ill patients [49], due to the high rate of permanent colostomy [50], poor quality of life [51, 52] and higher rate of post-operative complications associated with the Hartmann's reversal [53]. In selected patients (i.e., those with

\begin{tabular}{|c|c|c|c|c|c|c|c|c|}
\hline \multirow[b]{2}{*}{ Study or Subgroup } & \multicolumn{2}{|c|}{ PRA } & \multicolumn{2}{|l|}{ HP } & \multirow[b]{2}{*}{ Weight } & \multirow{2}{*}{$\begin{array}{c}\text { Odds Ratio } \\
\text { M-H, Random, } 95 \% \mathrm{Cl}\end{array}$} & \multirow{2}{*}{$\begin{array}{c}\text { Odds Ratio } \\
\text { M-H, Random, } 95 \% \mathrm{Cl}\end{array}$} & Risk of Bias \\
\hline & Events & Total & Events & Total & & & & $A B C D E F$ \\
\hline Binda 2012 & 1 & 22 & 8 & 34 & $11.6 \%$ & $0.15[0.02,1.34]$ & - & \\
\hline Bridoux 2017 & 4 & 32 & 7 & 33 & $30.1 \%$ & $0.53[0.14,2.03]$ & & \\
\hline Lambrichts 2019 & 3 & 38 & 13 & 44 & $29.8 \%$ & $0.20[0.05,0.78]$ & & \\
\hline Oberchofler 2012 & 6 & 26 & 6 & 15 & $28.4 \%$ & $0.45[0.11,1.79]$ & & \\
\hline Total $(95 \% \mathrm{Cl})$ & & 118 & & 126 & $100.0 \%$ & $0.33[0.16,0.69]$ & & \\
\hline Total events & 14 & & 34 & & & & & \\
\hline $\begin{array}{l}\text { Heterogeneity: Tau } \\
\text { Test for overall effec }\end{array}$ & $\begin{array}{l}0.00 ; \mathrm{Ch} \\
\mathrm{Z}=2.96\end{array}$ & $\begin{array}{l}P=1.66 \\
P=0.0\end{array}$ & $\begin{array}{l}0, \mathrm{df}=3( \\
03)\end{array}$ & $P=0.6$ & $5) ;\left.\right|^{2}=0 \%$ & & 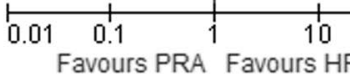 & 100 \\
\hline
\end{tabular}

Risk of bias legend
(A) Random sequence generation (selection bias)
(B) Allocation concealment (selection bias)
(C) Blinding of participants and personnel (performance bias)
(D) Blinding of outcome assessment (detection bias)
(E) Incomplete outcome data (attrition bias)
(F) Selective reporting (reporting bias)

Fig. 4 Forest plot of comparison: stoma-free patients who underwent sigmoid resection with primary anastomosis versus Hartmann's procedure for perforated diverticulitis with purulent or fecal peritonitis in randomized controlled trials (modified from Lambrichts et al.: Sig- moid resection with primary anastomosis versus the Hartmann's procedure for perforated diverticulitis with purulent or fecal peritonitis: a systematic review and meta-analysis) [48]

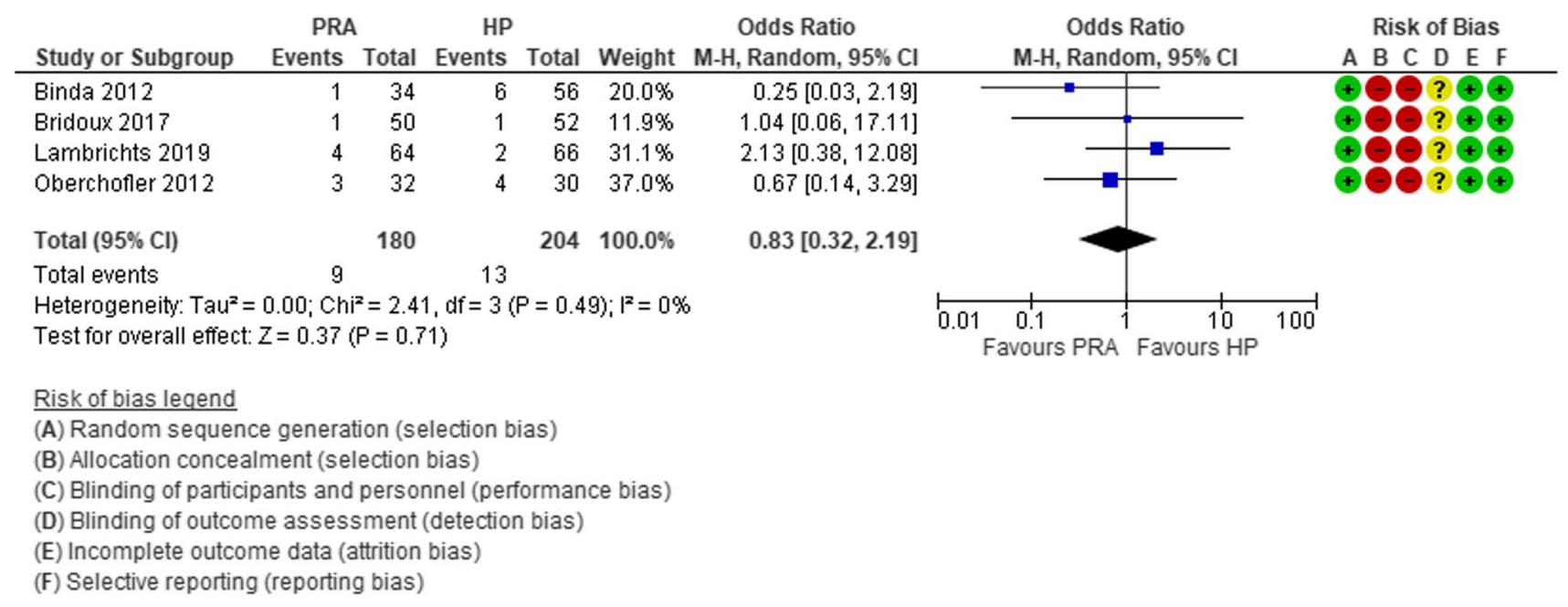

Fig. 5 Forest plot of comparison: overall short-term mortality rates in patients who underwent sigmoid resection with primary anastomosis versus Hartmann's procedure for perforated diverticulitis with purulent or fecal peritonitis in randomized controlled trials (modified from
Lambrichts et al.: Sigmoid resection with primary anastomosis versus the Hartmann's procedure for perforated diverticulitis with purulent or fecal peritonitis: a systematic review and meta-analysis) [48] 


\begin{tabular}{|c|c|c|c|c|c|c|c|c|}
\hline \multirow[b]{2}{*}{ Study or Subgroup } & \multicolumn{2}{|c|}{ PRA } & \multicolumn{2}{|c|}{ HP } & \multicolumn{2}{|r|}{ Odds Ratio } & \multirow{2}{*}{$\begin{array}{c}\text { Odds Ratio } \\
\text { M-H, Random, } 95 \% \mathrm{Cl}\end{array}$} & Risk of Bias \\
\hline & Events & Total & Events & Total & Weight & M-H, Random, $95 \% \mathrm{Cl}$ & & $A B C D E F$ \\
\hline Binda 2012 & 12 & 34 & 26 & 56 & $23.3 \%$ & $0.63[0.26,1.51]$ & (1) & 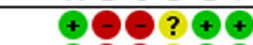 \\
\hline Bridoux 2017 & 27 & 50 & 22 & 52 & $29.4 \%$ & $1.60[0.73,3.50]$ & & \\
\hline Lambrichts 2019 & 25 & 64 & 29 & 66 & $36.8 \%$ & $0.82[0.41,1.65]$ & & \\
\hline Oberchofler 2012 & 27 & 32 & 24 & 30 & $10.5 \%$ & $1.35[0.36,4.99]$ & & 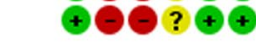 \\
\hline Total $(95 \% \mathrm{Cl})$ & & 180 & & 204 & $100.0 \%$ & $0.99[0.65,1.51]$ & & \\
\hline Total events & 91 & & 101 & & & & & \\
\hline $\begin{array}{l}\text { Heterogeneity: Tauz } \\
\text { Test for overall effec }\end{array}$ & $\begin{array}{l}0.00 ; \mathrm{Ch} \\
Z=0.06\end{array}$ & $\begin{array}{l}i^{2}=2.9 \\
(P=0.9\end{array}$ & $\begin{array}{l}8, d f=3( \\
95)\end{array}$ & $P=0.4$ & $0 ; F^{2}=0 \%$ & & 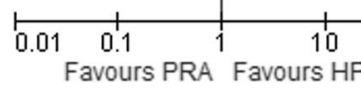 & $\overrightarrow{100}$ \\
\hline
\end{tabular}

\section{Risk of bias legend}

(A) Random sequence generation (selection bias)

(B) Allocation concealment (selection bias)

(C) Blinding of participants and personnel (performance bias)

(D) Blinding of outcome assessment (detection bias)

(E) Incomplete outcome data (attrition bias)

(F) Selective reporting (reporting bias)

Fig. 6 Forest plot of comparison: overall short-term morbidity rates in patients who underwent sigmoid resection with primary anastomosis versus Hartmann's procedure for perforated diverticulitis with purulent or fecal peritonitis in randomized controlled trials (modified from Lambrichts et al.: Sigmoid resection with primary anastomosis versus the Hartmann's procedure for perforated diverticulitis with purulent or fecal peritonitis: a systematic review and meta-analysis) [48] severe local inflammation), PRA with diverting loop ileostomy can represent an alternative to HP with a reduced risk of anastomotic leak and related complications [26].

This new trend favoring the PRA is also supported by the clinical practice guideline recommendations recently published by the American Society of Colon and Rectal Surgeons (ASCRS) [17], the World Society Emergency Surgery (WSES) [23], the European Society of Coloproctology [18], and the European Association for Endoscopic Surgery/Society of American Gastrointestinal and Endoscopic Surgeons (EAES/SAGES) [54] (Table 1).

\section{Responsive to fluids, hemodynamically unstable}

In some septic patients with temporary hemodynamic instability returning to normal pressure after crystalloid infusion (at least $30 \mathrm{~mL} / \mathrm{kg}$ or bolus of $500 \mathrm{~mL}$ ), the best treatment is emergency resection of the perforated colonic segment and abdominal washout. The decision between a restorative (PRA) and non-restorative (HP) procedure is strictly linked to the physiological reserve associated with comorbidities and severity of generalized peritonitis. In elderly patients, the evaluation of comorbidities, as proposed by the Comprehensive Geriatric Assessment (CGA), represents a crucial point in the assessment [55]. The identification of the different comorbidity classes (fit, vulnerable, and frail) is extremely important: fit patients have a lower operative risk and are candidate to PRA; conversely, frail patients have a high operative risk [56] and need a HP [54].

\section{Non-responsive to fluids and needing vasopressors, hemodynamically unstable}

In case of hemodynamic instability unresponsive to fluid administration, damage control surgery (DCS) is more effective than the Hartmann's procedure. DCS is a multistep strategy (abbreviated laparotomy, resuscitation in intensive care unit and definitive reconstruction) initially described for major trauma and lately applied to the surgical treatment of non-traumatic emergencies with severe sepsis or septic shock [57]. The first stage entails the local control of the septic source (peritoneal cleaning, limited resection of the perforated colonic segment with stapled off stumps) and Temporary Abdominal Closure (TAC); after 24-48 h of resuscitation in the ICU, a definitive surgical treatment is performed. In major trauma, the "lethal triad" (acidosis, hypothermia, and coagulopathy) creates a deadly cycle. Aim of DCS is to avoid very long extensive procedures in unstable patients undergoing resuscitation. DCS was proposed as a potential treatment for diffuse peritonitis due to perforated $\mathrm{AD}$ [58], but strategies and techniques have not been yet standardized [59] and the results are conflicting [60].

The recommendation to perform DCS in selected cases was first proposed in 2017 by the World Society of Emergency Surgery (WSES) Conference on the Management of Intra-abdominal infections [61], and successively was strongly supported by an update of the same surgical society (Consensus Conference 2020 update WSES [23]) and by the Consensus Conferences of EAES and SAGES [54].

DCS is associated with a reduction of post-operative mortality in patients poor general conditions $(9.2 \%$ [95\% CI 6.0 


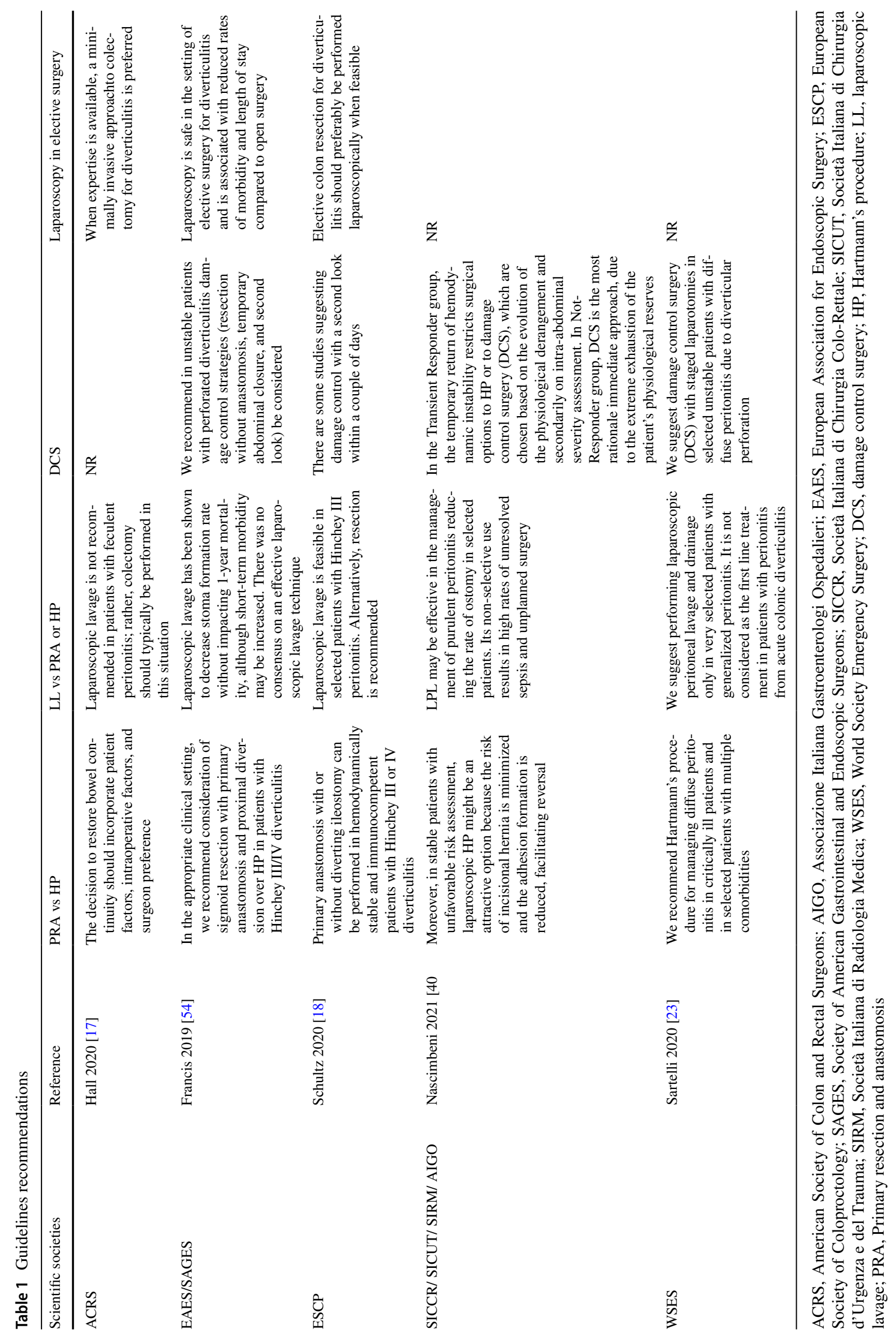




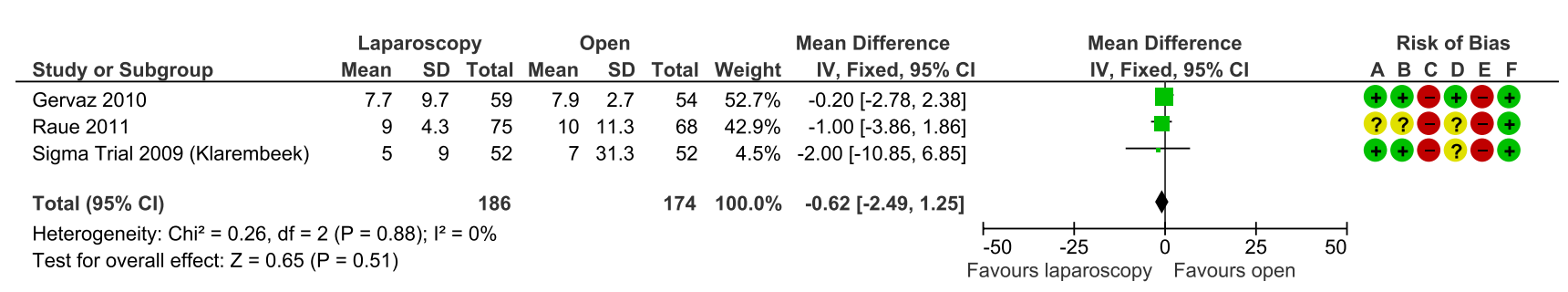

Risk of bias legend

(A) Random sequence generation (selection bias)

(B) Allocation concealment (selection bias)

(C) Blinding of participants and personnel (performance bias)

(D) Blinding of outcome assessment (detection bias)

(E) Incomplete outcome data (attrition bias)

(F) Selective reporting (reporting bias)

Fig. 7 Forest plot of comparison: length of hospital stay in laparoscopic vs open resection for sigmoid diverticulitis (Modified from Abraha et al.: Laparoscopic versus open resection for sigmoid diverticulitis) [77]

to $12.4 \%]$ ). Another substantial advantage is the overall high rate of primary resection and anastomosis $(62.1 \%$ [95\% CI 40.8 to $83.3 \%$ ]) [62, 63]. To date, criteria and techniques of DCS in the treatment of perforated diverticulitis with generalized peritonitis are yet to be defined [64].

\section{Surgical techniques}

In the management of $\mathrm{AD}$, another dilemma is the choice of the surgical access (i.e., conventional open or laparoscopic). Laparoscopic sigmoid resection is the preferred procedure in the elective setting. Since 1991, after the first report of laparoscopic colectomy [65], laparoscopic surgical access has gained a key role in the treatment of uncomplicated recurrent diverticular disease. This approach is commonly performed in the uncomplicated stages of acute diverticulitis with recurrent inflammatory episodes, but yet, diverticulitis complicated by complex abdominal abscesses with/without fistula (Hinchey IIb) does not represent an absolute contraindication to the laparoscopic approach [66].

Multiple observational studies have reviewed the outcomes of laparoscopic sigmoid resection for uncomplicated diverticulitis [67-69]. A systematic review and meta-analysis of these non-randomised studies reported clear advantages of laparoscopy over open surgery in terms of significantly lower rate of overall morbidity [17\% vs $27 \%$; OR $0.46,95 \%$ CI 0.25 to $0.84 ; 11$ studies; $I^{2}=74 \%$ ] and minor complications [ $9 \%$ vs $18 \%$; OR $0.37,95 \%$ CI 0.18 to 0.78 ; nine studies; $I^{2}=55 \%$ ]. However, these data might be influenced by the selection bias of the retrospective or prospective cohort studies included into the analyses [70].

Subsequently, Klarenbeek [71-73], Gervaz [74, 75], and Raue [76] presented the final results of three RCTs evaluating the benefits of elective laparoscopic vs open sigmoid resection for diverticulitis. In the Sigma trial, Klarenbeek showed that Quality of Life (QoL), measured by the Short
Form-36 questionnaire 6 weeks after surgery, improved significantly after laparoscopic resection in terms of limitations due to physical health (PRF) $(p=0.039)$, emotional problems $(p=0.024)$, social functioning $(p=0.015)$, and pain $(p=0.032)$. On the other side, Gervaz and Raue did not report differences in QoL using the European Organization for Research and Treatment of Cancer Core Quality of Life Questionnaire (EORTC QLQ-C30) v3 and the Gastrointestinal Quality of Life Index score, respectively. The meta-analysis of these three RCTs did not show any evidence to support the use of laparoscopic surgery in terms of a shorter length of stay (MD-0.62, 95\% CI - 2.49 to 1.25; $I^{2}=0 \%$ ) (Fig. 7) or other postoperative outcomes including post-operative surgical complications (RR 0.84, 95\% CI 0.60 to $1.19 ; I^{2}=0 \%$ ) (Fig. 8), 30-day postoperative mortality (RR $0.24,95 \%$ CI 0.03 to $2.07 ; I^{2}=0 \%$ ), and operative time (MD $49.28 \mathrm{~min}, 95 \%$ CI 40.64 to $57.93 ; I^{2}=0 \%$ ). The metaanalysis on postoperative pain showed that laparoscopic surgery can reduce pain at postoperative day $4(\mathrm{MD}-0.65,95 \%$ CI -1.04 to $-0.25 ; I^{2}=0 \%$ ) [77]. However, since the publication of these three RCTs, laparoscopic surgery greatly improved, and currently, many scientific societies support the safety and the advantages of the laparoscopic approach (Consensus Conference of EAES and SAGES [54], ESCP [18] and ASCRS [17]).

In the emergency setting and in hemodynamically stable patients, a laparoscopic approach is preferred, and surgeons with advanced laparoscopic skills reported some advantages in terms of lower postoperative complication rates; a systematic review and meta-analysis including 436 patients recruited from four observational studies highlighted that the laparoscopy resection slightly improves the rates of overall post-operative complications and post-operative length of stay, respectively (RR $0.62,95 \%$ CI 0.49 to 0.80 and MD $-6.53,95 \%$ CI -16.05 to 2.99) (Fig. 9). However, this approach does not seem to affect other clinical outcomes (i.e., rate of Hartmann's 
vs anastomosis, operating time, reoperation rate, and postoperative 30-day mortality) (Fig. 10) [78]. Furthermore, the Italian multisocietary position statement of Società Italiana di Chirurgia Colo-Rettale (SICCR), Società Italiana di Chirurgia d'Urgenza e del Trauma (SICUT), SIRM (Società Italiana di Radiologia Medica), and Associazione Italiana Gastroenterologi Ospedalieri (AIGO) recommended this approach if performed by rate and post-operative morbidity, as reported by the Consensus Conferences of EAES (European Association for Endoscopic Surgery) and SAGES (Society of American Gastrointestinal and Endoscopic Surgeons) [54]. This technique is feasible and safe, but advantages have been reported only in a selected group of patients, the success factors of LPL being still undefined [79]. In actual facts, a non-selective use of this technique causes a significant increase of postopera-

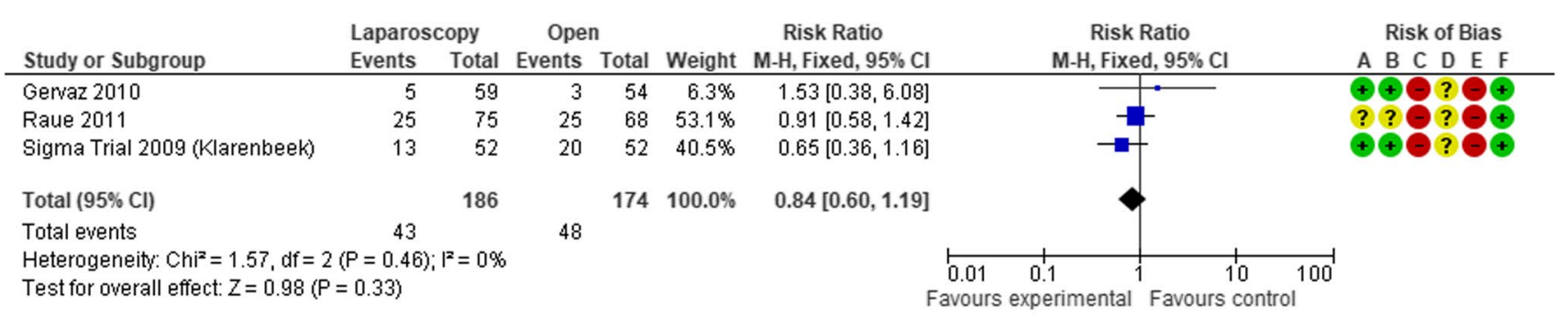

\section{Risk of bias legend}

(A) Random sequence generation (selection bias)

(B) Allocation concealment (selection bias)

(C) Blinding of participants and personnel (performance bias)

(D) Blinding of outcome assessment (detection bias)

(E) Incomplete outcome data (attrition bias)

(F) Selective reporting (reporting bias)

Fig. 8 Forest plot of comparison: length of hospital stay in laparoscopic vs open resection for sigmoid diverticulitis (Modified from Abraha et al.: Laparoscopic versus open resection for sigmoid diverticulitis) [77]

\begin{tabular}{|c|c|c|c|c|c|c|c|c|c|}
\hline \multirow[b]{2}{*}{ Study or Subgroup } & \multicolumn{2}{|c|}{ Laparoscopy } & \multicolumn{2}{|c|}{ Open } & \multirow[b]{2}{*}{ Weight } & \multirow{2}{*}{$\begin{array}{c}\text { Risk Ratio } \\
\text { M-H, Random, } 95 \% \mathrm{Cl}\end{array}$} & \multirow{2}{*}{\multicolumn{3}{|c|}{$\begin{array}{c}\text { Risk Ratio } \\
\text { M-H, Random, } 95 \% \mathrm{Cl}\end{array}$}} \\
\hline & Events & Total & Events & Total & & & & & \\
\hline Cassini 2017 & 12 & 36 & 16 & 24 & $20.9 \%$ & $0.50[0.29,0.86]$ & $\because-$ & & \\
\hline Letarte 2015 & 10 & 39 & 45 & 86 & $18.8 \%$ & $0.49[0.28,0.87]$ & $\longrightarrow-$ & & \\
\hline Turley 2013 & 17 & 67 & 20 & 67 & $20.2 \%$ & $0.85[0.49,1.47]$ & $\rightarrow$ & & \\
\hline Vennix 2016 & 17 & 39 & 51 & 78 & $40.0 \%$ & $0.67[0.45,0.99]$ & - & & \\
\hline Total $(95 \% \mathrm{Cl})$ & & 181 & & 255 & $100.0 \%$ & $0.62[0.49,0.80]$ & & & \\
\hline Total events & 56 & & 132 & & & & & & \\
\hline $\begin{array}{l}\text { Heterogeneity: Tauz } \\
\text { Test for owerall effec }\end{array}$ & $\begin{array}{l}0.00 ; \mathrm{Chi}^{2} \\
\mathrm{Z}=3.75(\end{array}$ & $\begin{array}{l}=2.65 \\
=0.00\end{array}$ & $\begin{array}{l}d f=3(P \\
02)\end{array}$ & $=0.45)$ & $;\left.\right|^{2}=0 \%$ & & $\begin{array}{ll}0.01 & 0.1 \\
\text { Favours laparoscopy }\end{array}$ & 10 & 100 \\
\hline
\end{tabular}

Fig. 9 Forest plot of comparison: Post-operative complications in laparoscopic vs open sigmoidectomy in the emergency treatment of complicated sigmoid diverticulitis (Modified from Cirocchi et al: The

qualified laparoscopic surgeons (In hemodynamically stable patients, confirmation and staging of diffuse peritonitis may be obtained by laparoscopy. In centers with adequate expertise selected cases may be handled by emergency laparoscopic procedures, either resective or non-resective) [40].

After the drainage of peritoneal collections, some surgeons advocated the use of laparoscopic lavage to improve the condition of septic patients through a dialytic reduction of endotoxin levels in the peritoneal fluid. The aim of the intraoperative laparoscopic lavage is the reduction of stoma role of emergency laparoscopic colectomy for complicated sigmoid diverticulitis: A systematic review and meta-analysis) [78]

tive intra-abdominal abscesses (RR 2.54, 95\% CI 1.34-4.83) (Fig. 11) [80]. Different results reported in the three RCTs (LADIES) [81-83] (SCANDIV) [84, 85] (DILALA) [86, 87] may possibly be due to the use of different selection criteria. The most recent guidelines suggest laparoscopic peritoneal lavage only in selected patients with Hinchey III peritonitis (American Society of Colon and Rectal Surgeons [17], World Society Emergency Surgery [23] and European Society of Coloproctology [18]). 


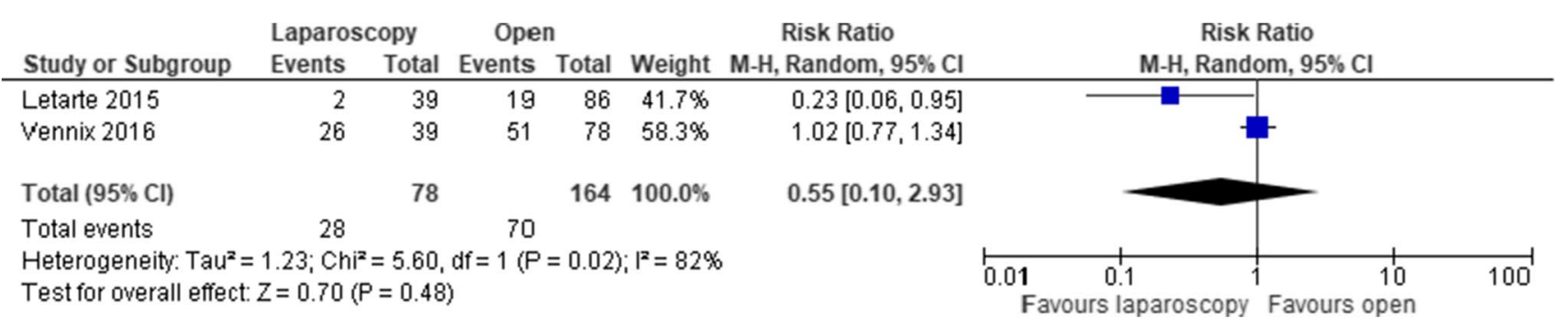

Fig. 10 Forest plot of comparison: Rate of Hartmann procedure vs PRA after laparoscopic vs open sigmoidectomy (modified from Cirocchi et al.: The role of emergency laparoscopic colectomy for complicated sigmoid diverticulitis: A systematic review and meta-analysis) [78]

\section{Complications}

Despite technical improvements and new surgical devices, anastomotic leak (AL) remains the most common cause of post-operative mortality and complications after sigmoidectomy [88]. Even if several studies identified several risk factors for AL (such as male sex, elderly age, obesity, severe comorbidities, prolonged surgery time, perioperative blood transfusions, and low anastomosis), an accurate anastomotic technique (tension-free, adequate blood supply, inverted anastomosis) is mandatory in order to reduce the incidence of AL [89]. Moreover, an anastomosis should be avoided in patients in critical conditions, under inotropes and on longterm steroid treatment.

\section{Pitfalls}

The ESCP recommended the preservation of IMA (In cases where there is no suspicion of cancer, IMA-preserving surgery can be performed to optimize preservation of the vascularization and the autonomic nerves) [18] although a meta-analysis failed to demonstrate the advantages of IMA preservation at reducing the risk of anastomotic leakage (RR 0.59, 95\% CI 0.26-1.33) (Fig. 12) [90]. The IMA-preserving technique is performed by ligating the sigmoid vessels close to the colon, but this manoeuvre can be challenging due to mesosigmoid fibrosis commonly associated with the inflammation of the myoenteric plexus (40\%) [91]. For this reason, the skeletonization of the sigmoid mesentery close to the bowel wall might be safer with the use of "cut and tie" devices [92]. Another option would be the much easier low ligation of the IMA after the origin of the left colic artery. With this manoeuvre, the IMA is prepared at its bifurcation, well away from the preaortic and hypogastric nervus plexa, where it can be easily ligated along with the IMV that runs exactly above the bifurcation. This approach looks much more prudent than the intramesosigmoid dissection also as it guarantees an adequate lymphadenectomy in the case of an unexpected carcinoma in the surgical specimen.

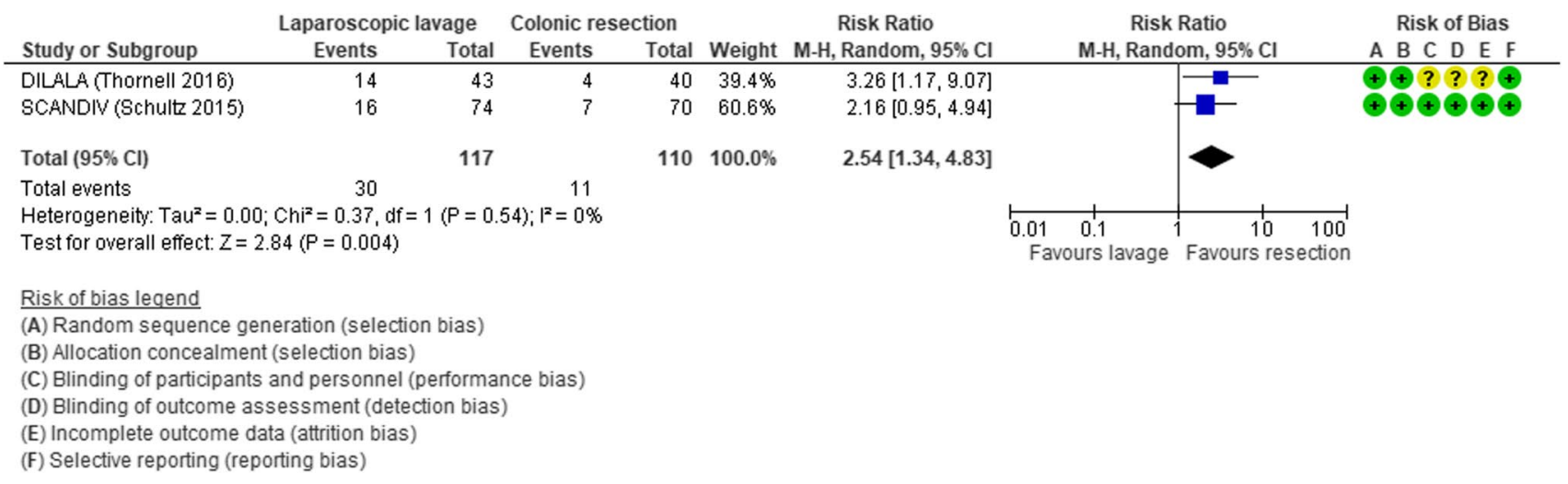

Fig. 11 Forest plot of comparison: 90-day postoperative intra-abdominal abscess in laparoscopic lavage vs surgical resection for acute diverticulitis with generalized peritonitis (modified from Cirocchi et al.: Laparoscopic lavage versus surgical resection for acute diverticulitis with generalized peritonitis: a systematic review and metaanalysis) [80] 


\begin{tabular}{|c|c|c|c|c|c|c|c|c|c|}
\hline Study or Subgroup & \multicolumn{2}{|c|}{ IMA preserving } & \multicolumn{2}{|c|}{ IMA tie } & Weight & $\begin{array}{l}\text { Risk Ratio } \\
\text { Random, } 95 \% \mathrm{Cl}\end{array}$ & \multicolumn{2}{|c|}{$\begin{array}{c}\text { Risk Ratio } \\
\text { M-H, Random, } 95 \% \mathrm{Cl}\end{array}$} & \\
\hline Borchert 2015 & 1 & 100 & 8 & 113 & $9.9 \%$ & $0.14[0.02,1.11]$ & & & \\
\hline De Nardi 2015 & 6 & 153 & 3 & 66 & $15.7 \%$ & $0.86[0.22,3.35]$ & & & \\
\hline Lehmann 2011 & 5 & 44 & 2 & 86 & $13.4 \%$ & $4.89[0.99,24.18]$ & & & \\
\hline Pignata 2006 & 0 & 23 & 1 & 60 & $5.3 \%$ & $0.85[0.04,20.08]$ & & & \\
\hline Posabella 2018 & 9 & 736 & 4 & 280 & $17.7 \%$ & $0.86[0.27,2.76]$ & & & \\
\hline Sohn 2017 & 3 & 157 & 7 & 102 & $16.0 \%$ & $0.28[0.07,1.05]$ & & & \\
\hline Tocchi 2001 & 7 & 86 & 22 & 77 & $22.1 \%$ & $0.28[0.13,0.63]$ & & & \\
\hline Total $(95 \% \mathrm{Cl})$ & & 1299 & & 784 & $100.0 \%$ & $0.59[0.26,1.33]$ & & & \\
\hline Total events & 31 & & 47 & & & & & & \\
\hline $\begin{array}{l}\text { Heterogeneity: Tau² } \\
\text { Test for overall effec }\end{array}$ & $\begin{array}{l}0.60 ; \mathrm{Chi}^{\circ} \\
z=1.27\end{array}$ & $\begin{array}{l}13.46 \\
0.20)\end{array}$ & $f=6(P$ & $=0.04$ & $=55 \%$ & & $\begin{array}{ll}0.01 & 1 \\
\text { Favours IMA preserving }\end{array}$ & $\begin{array}{c}10 \\
\text { Favours IMA tie }\end{array}$ & 100 \\
\hline
\end{tabular}

Fig. 12 Forest plot of comparison: anastomotic leakage in IMA preserving group vs tie group (modified from Cirocchi et al.: Sigmoid resection for diverticular disease - to ligate or to preserve the inferior mesenteric artery? Results of a systematic review and meta-analysis) [90]

\section{Conclusions}

In conclusion, the decision on whether to proceed with surgery in patients with DD should be individualized based on the most recent evidence. At present, judicious surgeons should exhaustively explain and discuss with the patients and their relatives about the uncertain benefits and the potential risks of the different type of surgical treatments and surgical access before performing the intervention in elective or emergency setting.

New studies are needed, especially in the long-term period, to provide additional data that can confirm the results of actually evidence reported.

Funding Open access funding was provided by Università degli Studi of Perugia within the CRUI-CARE Agreement.

\section{Declarations}

Ethics approval This article does not contain any studies with human participants or animals performed by any of the authors.

Competing interests The authors declare no competing interests.

Open Access This article is licensed under a Creative Commons Attribution 4.0 International License, which permits use, sharing, adaptation, distribution and reproduction in any medium or format, as long as you give appropriate credit to the original author(s) and the source, provide a link to the Creative Commons licence, and indicate if changes were made. The images or other third party material in this article are included in the article's Creative Commons licence, unless indicated otherwise in a credit line to the material. If material is not included in the article's Creative Commons licence and your intended use is not permitted by statutory regulation or exceeds the permitted use, you will need to obtain permission directly from the copyright holder. To view a copy of this licence, visit http://creativecommons.org/licenses/by/4.0/.

\section{References}

1. Strate LL, Morris AM (2019) Epidemiology, pathophysiology, and treatment of diverticulitis. Gastroenterology 156(5):1282-1298

2. Munie ST, Nalamati SPM (2018) Epidemiology and pathophysiology of diverticular disease. Clin Colon Rectal Surg 31(4):209-213

3. Martellotto S, Challine A, Peveri V et al (2021) Trends in emergent diverticular disease management: a nationwide cohort study from 2009 to 2018. Tech Coloproctol 25(5):549-558

4. Amato A, Mataloni F, Bruzzone M et al (2020) Hospital admission for complicated diverticulitis is increasing in Italy, especially in younger patients: a national database study. Tech Coloproctol 24(3):237-245

5. Diamant MJ, Coward S, Buie WDGG et al (2015) Hospital volume and other risk factors for in-hospital mortality among diverticulitis patients: a nationwide analysis. Can J Gastroenterol Hepato 29:193-197

6. Bouchagier K, Filippou D, Skandalakis P (2018) The relation between the sigmoid volvulus and the anatomical morphometric measurements of the sigmoid colon: a review. Int J Surg Med $4(2): 88-92$

7. Grassi V, Tabola R, Basile E et al (2018) Sigmoid diverticulitis in elderly patients: a rare cause of right iliac fossa pain. Minerva Chir 73(4):444-447

8. Kreis Me, Jauch KW (2006) Diverticular disease - Update 2006. In: Neugebauer EAM, Sauerland S , Fingerhut A, Millat B, Buess GF, editors(s). EAES Guidelines for Endoscopic Surgery. Springer, 157-160

9. Broderick-Villa G, Burchette RJ, Collins JC et al (2005) Hospitalization for acute diverticulitis does not mandate routine elective colectomy. Arch Surg 140:576-581

10 Parks TG (1969) Natural history of diverticular disease of the colon. A review of 521 cases. Br Med J. 4(5684):639-42

11 Roberts P, Abel M, Rosen L et al (1995) Practice parameters for sigmoid diverticulitis. The Standards Task Force American Society of Colon and Rectal Surgeons. Dis Colon Rectum 38(2): 125-32

12. Köhler L, Sauerland S, Neugebauer E (1999) Diagnosis and treatment of diverticular disease: results of a consensus development conference. The Scientific Committee of the European Association for Endoscopic Surgery. Surg Endosc 13(4):430-6

13. Margolin DA (2009) Timing of elective surgery for diverticular disease. Clin Colon Rectal Surgery 22:169-172

14. SSAT Patient Care Guidelines (2007) Surgical Treatment of Diverticulitis. http://www.ssat.com/cgi-bin/divert.cgi 
15 Rafferty J, Shellito P, Hyman NH et al (2006) Standards committee of american society of colon and rectal surgeons. Practice parameters for sigmoid diverticulitis. Dis Colon Rectum 49(7):939-44

16. Feingold D, Steele SR, Lee S et al (2014) Rafferty JF. Practice parameters for the treatment of sigmoid diverticulitis. Dis Colon Rectum 57(3): 284-94

17. Hall J, Hardiman K, Lee S, Lightner A, et al. (2020 Jun) Prepared on behalf of the Clinical Practice Guidelines Committee of the American Society of Colon and Rectal Surgeons. The American Society of Colon and Rectal Surgeons clinical practice guidelines for the treatment of left-sided colonic diverticulitis. Dis Colon Rectum 63(6): 728-747.

18. Schultz JK, Azhar N, Binda GA et al (2020) European Society of Coloproctology: guidelines for the management of diverticular disease of the colon. Colorectal Dis 22(Suppl 2):5-28

19. Azhar N, Kulstad H, Pålsson B, Kurt Schultz J, Lydrup ML, Buchwald P (2019) Acute uncomplicated diverticulitis managed without antibiotics - difficult to introduce a new treatment protocol but few complications. Scand J Gastroenterol 54(1):64-68

20. Lamb MN, Kaiser AM (2014) Elective resection versus observation after nonoperative management of complicated diverticulitis with abscess: a systematic review and meta-analysis. Dis Colon Rectum 57(12):1430-1440

21. Fowler H, Gachabayov M, Vimalachandran D, Clifford R, Orangio GR, Bergamaschi R (2021) Failure of nonoperative management in patients with acute diverticulitis complicated by abscess: a systematic review. Int J Colorectal Dis 36(7):1367-1383

22. Peery AF, Shaukat A, Strate LL (2021) AGA clinical practice update on medical management of colonic diverticulitis: expert review. Gastroenterology 160(3):906-911.e1

23. Sartelli M, Weber DG, Kluger Y et al (2020) 2020 update of the WSES guidelines for the management of acute colonic diverticulitis in the emergency setting. World J Emerg Surg. $7 ; 15(1): 32.23$

24. Gaertner WB, Willis DJ, Madoff RD, Rothenberger DA, Kwaan MR, Belzer GE, Melton GB (2013) Percutaneous drainage of colonic diverticular abscess: is colon resection necessary? Dis Colon Rectum 56(5):622-626

25. Hanna MH, Kaiser AM (2021) Update on the management of sigmoid diverticulitis. World J Gastroenterol 27(9):760-781

26. Rottier SJ, van Geloven AAW, Schreurs WH et al (2019) Mistakes in acute diverticulitis and how to avoid them. UEG Education 19(31-35):26

27. Anaya DA, Flum DR (2005) Risk of emergency colectomy and colostomy in patients with diverticular disease. Arch Surg 140(7):681-685

28. Bolkenstein HE, Consten ECJ, van der Palen J, van de Wall BJM, Broeders IAMJ, Bemelman WA, Lange JF, Boermeester MA, Draaisma WA (2019) Dutch Diverticular Disease (3D) Collaborative Study Group. Long-term outcome of surgery versus conservative management for recurrent and ongoing complaints after an episode of diverticulitis: 5-year follow-up results of a multicenter randomized controlled trial (DIRECT-Trial). Ann Surg. 269(4):612-620.

29. Santos A, Mentula P, Pinta T, Ismail S, Rautio T, Juusela R, Lähdesmäki A, Scheinin T, Sallinen V (2021) Comparing laparoscopic elective sigmoid resection with conservative treatment in improving quality of life of patients with diverticulitis: the laparoscopic elective sigmoid resection following diverticulitis (LASER) randomized clinical trial. JAMA Surg 156(2):129-136

30. Zaborowski AM, Winter DC (2021) Evidence-based treatment strategies for acute diverticulitis. Int J Colorectal Dis 36(3):467-475
31. Tursi A, Scarpignato C, Strate LL, Lanas A, Kruis W, Lahat A, Danese S (2020) Colonic diverticular disease. Nat Rev Dis Primers 6(1):20

32. Nally DM, Kavanagh DO (2019) Current controversies in the management of diverticulitis: a review. Dig Surg 36(3):195-205

33. Seymour CW, Kahn JM, Martin-Gill C et al (2017) Delays from first medical contact to antibiotic administration for sepsis. Crit Care Med 45(5):759-765

34. Kumar A, Roberts D, Wood KE et al (2006) Duration of hypotension before initiation of effective antimicrobial therapy is the critical determinant of survival in human septic shock. Crit Care Med 34(6):1589-1596

35. Rhodes A, Evans LE, Alhazzani W et al (2017) Surviving sepsis campaign: international guidelines for management of sepsis and septic shock: 2016. Intensive Care Med 43(3):304-377

36. Meyhoff TS, Møller MH, Hjortrup PB et al (2020) Lower vs higher fluid volumes during initial management of sepsis: a systematic review with meta-analysis and trial sequential analysis. Chest 157(6):1478-1496

37. Douglas IS, Alapat PM, Corl KA, et al (Chest 2020) Fluid response evaluation in sepsis hypotension and shock: a randomized clinical trial 158(4):1431-1445

38. Saugel B, Huber W, Nierhaus A et al (2016) Advanced hemodynamic management in patients with septic shock. Biomed Res Int 2016:8268569

39. Lat I, Coopersmith CM, De Backer D et al (2021) The surviving sepsis campaign: fluid resuscitation and vasopressor therapy research priorities in adult patients. ICMx 9:10. https://doi.org/ 10.1186/s40635-021-00369-9

40 Nascimbeni R, Amato A, Cirocchi R (2021) Management of perforated diverticulitis with generalized peritonitis. A multidisciplinary review and position paper. Tech Coloproctol 25(2):153-165

41. Tursi A, Scarpignato C, Strate LL et al (2020) Colonic diverticular disease. Nat Rev Dis Primers. 26;6(1):20

42. Cirocchi R, Afshar S, Di Saverio S et al (2017) A historical review of surgery for peritonitis secondary to acute colonic diverticulitis: from Lockhart-Mummery to evidence-based medicine. World J Emerg Surg 9(12):14

43. Constantinides VA, Tekkis PP, Athanasiou T et al (2006) Primary resection with anastomosis vs. Hartmann's procedure in nonelective surgery for acute colonic diverticulitis: a systematic review. Dis Colon Rectum 49(7):966-81

44. Binda GA, Karas JR, Serventi A et al (2012) Primary anastomosis vs nonrestorative resection for perforated diverticulitis with peritonitis: a prematurely terminated randomized controlled trial. Colorectal Dis 14(11):1403-1410

45. Oberkofler CE, Rickenbacher A, Raptis DA et al (2012) A multicenter randomized clinical trial of primary anastomosis or Hartmann's procedure for perforated left colonic diverticulitis with purulent or fecal peritonitis. Ann Surg 256(5):819-826

46. Bridoux V, Regimbeau JM, Ouaissi M et al (2017) Hartmann's procedure or primary anastomosis for generalized peritonitis due to perforated diverticulitis: a prospective multicenter randomized trial (DIVERTI). J Am Coll Surg 225(6):798-805

47. Lambrichts DPV, Vennix S, Musters GD (2019) Hartmann's procedure versus sigmoidectomy with primary anastomosis for perforated diverticulitis with purulent or faecal peritonitis (LADIES): a multicentre, parallel-group, randomised, open-label, superiority trial. Lancet Gastroenterol Hepatol 4(8):599-610

48. Lambrichts DP, Edomskis PP, van der Bogt RD (2020) Sigmoid resection with primary anastomosis versus the Hartmann's procedure for perforated diverticulitis with purulent or fecal peritonitis: a systematic review and meta-analysis. Int J Colorectal Dis 35(8):1371-1386 
49. Acuna SA, Dossa F, Baxter NN (2019) The end of the Hartmann's era for perforated diverticulitis. Lancet Gastroenterol Hepatol 4(8):573-575

50. Maggard MA, Zingmond D, O'Connell JB, Ko CY (2004) What proportion of patients with an ostomy (for diverticulitis) get reversed? Am Surg 70(10):928-931

51. Vermeulen J, Coene PPLO, van Hout NM et al (2009) Restoration of bowel continuity after surgery for acute perforated diverticulitis: should Hartmann's procedure be considered a one-stage procedure? Colorectal Dis 11:619-624

52. Vermeulen J, Gosselink MP, Busschbach JJ wt al (2010) Avoiding or reversing Hartmann's procedure provides improved quality of life after perforated diverticulitis. J Gastrointest Surg14(4): 651-7

53. Whitney S, Gross BD, Mui A et al (2020) Hartmann's reversal: factors affecting complications and outcomes. Int J Colorectal Dis 35(10): $1875-1880$

54. Francis NK, Sylla P, Abou-Khalil M et al (2019) EAES and SAGES 2018 consensus conference on acute diverticulitis management: evidence-based recommendations for clinical practice. Surg Endosc 33(9):2726-2741

55. Audisio RA (2016) Tailoring surgery to elderly patients with cancer. Br J Surg 103:e10-e11

56. Hamerman D (1999) Toward an understanding of frailty. Ann Intern Med 130:945-50. 30.

57. Becher RD, Peitzman AB, Sperry JL et al (2016) Damage control operations in non-trauma patients: defining criteria for the staged rapid source control laparotomy in emergency general surgery. World J Emerg Surg 24(11):10

58. Vogler J 4th, Hart L, Holmes S et al (2018) Rapid source-control laparotomy: is there a mortality benefit in septic shock? Surg Infect (Larchmt) 19(2):225-229

59. Cirocchi R, Arezzo A, Vettoretto N et al (2014) Role of damage control surgery in the treatment of Hinchey III and IV sigmoid diverticulitis: a tailored strategy. Medicine (Baltimore) 93(25):e184

60. Rosenzweig M, Berg A, Kuo YH et al (2020) Are the benefits of rapid source control laparotomy realized after acute colonic perforation? Surg Infect (Larchmt) 21(8):665-670

61. Sartelli M, Catena F, Abu-Zidan FM et al (2017) Management of intra-abdominal infections: recommendations by the WSES 2016 consensus conference. World J Emerg Surg 4(12):22

62. Cirocchi R, Popivanov G, Konaktchieva M et al (2021) The role of damage control surgery in the treatment of perforated colonic diverticulitis: a systematic review and meta-analysis. Int J Colorectal Dis 36(5):867-879

63. Sohn M, Agha A, Iesalnieks I et al (2021 mar) Damage control strategy in perforated diverticulitis with generalized peritonitis. BMC Surg 16;21(1):135

64. Jacobs M, Verdeja JC, Goldstein HS (1991) Minimally invasive colon resection (laparoscopic colectomy). Surg Laparosc Endosc 1(3):144-150

65. Swank HA, Vermeulen J, Lange JF (2010) Dutch Diverticular Disease (3D) Collaborative Study Group. The ladies trial: laparoscopic peritoneal lavage or resection for purulent peritonitis and Hartmann's procedure or resection with primary anastomosis for purulent or faecal peritonitis in perforated diverticulitis (NTR2037). BMC Surg $18 ; 10: 29$

66. Weber WP, Guller U, Jain NB et al (2007) Impact of surgeon and hospital caseload on the likelihood of performing laparoscopic vs open sigmoid resection for diverticular disease: a study based on 55,949 patients. Arch Surg 142:253-259

67. McCafferty MH, Roth L, Jorden J (2008) Current management of diverticulitis. Am Surg 74:1041-1049

68. Touzios JG, Dozois EJ (2009) Diverticulosis and acute diverticulitis. Gastroenterol Clin North Am 38:513-525

69. Stocchi L (2010) Current indications and role of surgery in the management of sigmoid diverticulitis. World J Gastroenterol 16:804-817
70. Cirocchi R, Farinella E, Trastulli S et al (2012) Elective sigmoid colectomy for diverticular disease. Laparoscopic vs open surgery: a systematic review. Colorectal Dis 14:671-683

71. Klarenbeek BR, Veenhof AA, Bergamaschi R et al (2009) Laparoscopic sigmoid resection for diverticulitis decreases major morbidity rates: a randomized control trial. Short-term results of the Sigma trial. Ann Surg 249:39-44

72. Klarenbeek BR, Bergamaschi R, Veenhof AA et al (2011) Laparoscopic versus open sigmoid resection for diverticular disease: follow-up assessment of the randomized control Sigma trial. Surg Endosc 25:1121-1126

73. Klarenbeek BR, Coupé VM, Peet DL et al (2011) The cost effectiveness of elective laparoscopic sigmoid resection for symptomatic diverticular disease: financial outcome of the randomized control Sigma trial. Surg Endosc 25:776-783

74. Gervaz P, Inan I, Perneger T et al (2010) Prospective, randomized, single-blind comparison of laparoscopic versus open sigmoid colectomy for diverticulitis. Ann Surg 252:3-8

75. Gervaz P, Mugnier-Konrad B, Morel P et al (2011) Laparoscopic versus open sigmoid resection for diverticulitis: long-term results of a prospective, randomized trial. Surg Endosc 25:3373-3378

76. Raue W, Paolucci V, Asperger W et al (2011) Laparoscopic sigmoid resection for diverticular disease has no advantages over open approach: midterm results of a randomized controlled trial. Langenbeck's Arch Surg 396:973-980

77. Abraha I, Binda GA, Montedori A et al (2017). Laparoscopic versus open resection for sigmoid diverticulitis. Cochrane Database Syst Rev 11(11):CD009277

78. Cirocchi R, Fearnhead N, Vettoretto N et al (2019) The role of emergency laparoscopic colectomy for complicated sigmoid diverticulits: a systematic review and meta-analysis. Surgeon 17(6):360-369

79. Binda GA, Bonino MA, Siri G et al (2018). LLO Study Group. Multicentre international trial of laparoscopic lavage for Hinchey III acute diverticulitis (LLO Study). Br J Surg105(13): 1835-1843

80. Cirocchi R, Di Saverio S, Weber DG et al (2017) Laparoscopic lavage versus surgical resection for acute diverticulitis with generalised peritonitis: a systematic review and meta-analysis. Tech Coloproctol 21(2):93-110

81. Vennix S, Musters GD, Mulder IM et al (2015) Laparoscopic peritoneal lavage or sigmoidectomy for perforated diverticulitis with purulent peritonitis: a multicentre, parallel-group, randomised, openlabel trial. Lancet. 26;386(10000):1269-1277

82. Lambrichts DPV, Vennix S, Musters GD et al (2017) Management of intra-abdominal infections: recommendations by the WSES 2016 consensus conference. World J Emerg Surg 12:22

83. Vermeulen J, van Dieren S, Bemelman WA et al (2019) Hartmann's procedure versus sigmoidectomy with primary anastomosis for perforated diverticulitis with purulent or faecal peritonitis (LADIES): a multicentre, parallel-group, randomised, open-label, superiority trial. Lancet Gastroenterol Hepatol 4(8):599-610

84. Schultz JK, Yaqub S, Wallon C et al (2015) laparoscopic lavage vs primary resection for acute perforated diverticulitis: the SCANDIV randomized clinical trial. JAMA 6;314(13):1364-75

85. Azhar N, Johanssen A, Sundström T et al (2021) laparoscopic lavage vs primary resection for acute perforated diverticulitis: long-term outcomes from the Scandinavian Diverticulitis (SCANDIV) randomized clinical trial. JAMA Surg 1;156(2):121-127

86. Angenete E, Thornell A, Burcharth J et al (2016) laparoscopic lavage is feasible and safe for the treatment of perforated diverticulitis with purulent peritonitis: the first results from the randomized controlled trial DILALA. Ann Surg 263(1):117-122

87. Thornell A, Angenete E, Bisgaard T et al (2016) laparoscopic lavage for perforated diverticulitis with purulent peritonitis: a randomized trial. Ann Intern Med. 2;164 (3):137-45

88. Lehmann RK, Brounts LR, Johnson EK et al (2011) Does sacrifice of the inferior mesenteric artery or superior rectal artery affect 
anastomotic leak following sigmoidectomy for diverticulitis? a retrospective review. Am J Surg 201(5):623-627

89. Fang AH, Chao W, Ecker M (2020) Review of colonic anastomotic leakage and prevention methods. J Clin Med 16;9(12):4061

90. Cirocchi R, Popivanov G, Binda GA et al (2019) Sigmoid resection for diverticular disease - to ligate or to preserve the inferior mesenteric artery? Results of a systematic review and meta-analysis. Colorectal Dis 21(6):623-631

91. Bassotti G, Villanacci V, Sidoni A et al (2015) Myenteric plexitis: a frequent feature in patients undergoing surgery for colonic diverticular disease. United European Gastroenterol J 3(6):523-528
92. Bruch HP, Roblick UJ, Esnaashari H (2008) Dissecting the sigmoid mesentery. In: Immenroth M, Berg T, Brenner J (eds) Laparoscopic sigmoidectomy for diverticulitis. Spinger Midizin Verlag, Wurzburg (Germany), pp 40-41

Publisher's note Springer Nature remains neutral with regard to jurisdictional claims in published maps and institutional affiliations.

\section{Authors and Affiliations}

\section{Roberto Cirocchi ${ }^{1}$ (1) - Paolo Sapienza ${ }^{2}$. Gabriele Anania ${ }^{3}$. Gian Andrea Binda ${ }^{4,1}$. Stefano Avenia ${ }^{1}$. Salomone di Saverio ${ }^{5}$. Giovanni Domenico Tebala ${ }^{6} \cdot$ Mauro Zago $^{7}$. Annibale Donini ${ }^{1}$. Andrea Mingoli ${ }^{2}$. Riccardo Nascimbeni ${ }^{8}$}

Paolo Sapienza

paolo.sapienza@uniroma1.it

Gabriele Anania

ang@unife.it

Gian Andrea Binda

gianbinda1@gmail.com

Stefano Avenia

stefano_avenia@libero.it

Salomone di Saverio

salomone.disaverio@gmail.com

Giovanni Domenico Tebala

giovanni.tebala@ouh.nhs.uk

Mauro Zago

maurozago.md@gmail.com

Annibale Donini

annibale.donini@unipg.it

Andrea Mingoli

andrea.mingoli@uniroma1.it
Riccardo Nascimbeni

riccardo.nascimbeni@unibs.it

1 Department of Medicine and Surgery, University of Perugia, 06100 Perugia, Italy

2 Department of Surgery "Pietro Valdoni”, "Sapienza" University of Rome, 00161 Rome, Italy

3 Department of Medical Science, University of Ferrara, 4121 Ferrara, Italy

4 General Surgery, Biomedical Institute, 16157 Genoa, Italy

5 University of Insubria, Varese, Italy

6 Surgical Emergency Unit, John Radcliffe Hospital, Oxford University NHS Foundation Trust, Oxford, UK

7 Department of Robotic and Emergency Surgery, Manzoni Hospital, 23900 Lecco, Italy

8 Department of Molecular and Translational Medicine, University of Brescia, 25124 Brescia, Italy 